OPEN ACCESS

Edited by:

Junjie Xiao,

Shanghai University, China

Reviewed by:

Dušan Fabian,

Institute of Animal Physiology (SAS),

Slovakia

Xue-Ming Zhang,

Jilin University, China

*Correspondence:

Luc Peelman

Luc.Peelman@UGent.be

Specialty section: This article was submitted to RNA, a section of the journal

Frontiers in Genetics

Received: 13 May 2019

Accepted: 17 July 2019

Published: 22 August 2019

Citation:

Lin X, Pavani KC, Smits K, Deforce D, Heindryckx B, Van Soom A and Peelman L (2019) Bta-miR-10b

Secreted by Bovine Embryos Negatively Impacts Preimplantation Embryo Quality.

Front. Genet. 10:757.

doi: 10.3389/fgene.2019.00757

\section{Bta-miR-10b Secreted by Bovine Embryos Negatively Impacts Preimplantation Embryo Quality}

\author{
Xiaoyuan Lin ${ }^{1}$, Krishna Chaitanya Pavani ${ }^{2}$, Katrien Smits ${ }^{2}$, Dieter Deforce ${ }^{3}$, \\ Björn Heindryckx ${ }^{4}$, Ann Van Soom ${ }^{2}$ and Luc Peelman ${ }^{1 *}$ \\ ${ }^{1}$ Department of Nutrition, Genetics and Ethology, Faculty of Veterinary Medicine, Ghent University, Ghent, Belgium, \\ ${ }^{2}$ Reproduction, Obstetrics and Herd Health, Ghent University, Ghent, Belgium, ${ }^{3}$ Laboratory for Pharmaceutical \\ Biotechnology, Faculty of Pharmaceutical Sciences, Ghent University, Ghent, Belgium, ${ }^{4}$ Department for Reproductive \\ Medicine, Ghent University Hospital, Ghent, Belgium
}

In a previous study, we found miR-10b to be more abundant in a conditioned culture medium of degenerate embryos compared to that of blastocysts. Here, we show that miR-10b mimics added to the culture medium can be taken up by embryos. This uptake results in an increase in embryonic cell apoptosis and aberrant expression of DNA methyltransferases (DNMTs). Using several algorithms, Homeobox A1 (HOXA1) was identified as one of the potential miR-10b target genes and dual-luciferase assay confirmed HOXA1 as a direct target of miR-10b. Microinjection of si-HOXA1 into embryos also resulted in an increase in embryonic cell apoptosis and downregulation of DNMTs. Cell progression analysis using Madin-Darby bovine kidney cells (MDBKs) showed that miR-10b overexpression and HOXA1 knockdown results in suppressed cell cycle progression and decreased cell viability. Overall, this work demonstrates that miR-10b negatively influences embryo quality and might do this through targeting HOXA1 and/or influencing DNA methylation.

Keywords: bovine embryos, secreted miRNAs, miR-10b, HOXA1, DNA methylation, apoptosis

\section{INTRODUCTION}

MiRNAs, small non-coding RNAs, function as crucial (epigenetic) regulators that can be transferred between cells (Valadi et al., 2007). MiRNAs' selective secretion and high stability (resistant to RNase digestion and other harsh conditions) (Luo et al., 2009; Donker et al., 2012) make them good candidates as non-invasive biomarkers for preimplantation embryo quality assessment and thus increase efficiency and reduce both the risks and the costs associated with assisted reproductive treatment (ART) (Homer et al., 2017).

In a previous study, we identified 114 known and 180 novel secreted miRNAs present in bovine embryo culture media (CM). Of these miRNAs, miR-30c and miR-10b were much more abundant in $\mathrm{CM}$ of slow-cleaving embryos compared to intermediate-cleaving embryos. We further demonstrated that miR-30c directly targets Cyclin-dependent kinase 12 mRNA and downregulates several DNA damage response (DDR) genes (Lin et al., 2019). MiR-10b was also shown to be more abundant in the culture medium of degenerate embryos compared with that of blastocysts, and more abundant in the culture medium of slow-cleaving embryos compared with that of intermediate-cleaving embryos, indicating that overexpression of $\mathrm{miR}-10 \mathrm{~b}$ has a negative influence on preimplantation embryo development in cattle (Lin et al., 2019). Previously, miR-10b has been shown to regulate cell 
invasion, apoptosis, viability, and migration in multiple cell lines in human, mouse, and goat (Chen et al., 2016; Li et al., 2016; Peng et al., 2016; Zhen et al., 2016; Zhu et al., 2016; Tan et al., 2018).

Among the possible miR-10b target genes we identified using several computational methods, HOXA1 stood out as it was previously shown to be involved in cell proliferation in human epithelial cells (Bitu et al., 2012) and cell growth, invasion, and migration in esophageal cancer cells (Li et al., 2017). MiR$10 \mathrm{~b}$ is located within an intron of HOXD4 (Homeobox D4) in bovine (NC_037329.1) and mouse (NC_000068.7), and between HOXD4 and HOXD8 (Homeobox D8) in human (NC_000002.12). Human miR-10b has also been shown to target HOX genes (homeobox transcription factor) such as HOXD10 (Liu et al., 2012; Nakayama et al., 2013) and HOXB3 (Chen et al., 2016), thus regulating cell invasion, migration, proliferation, and apoptosis. HOXA1 is a conserved member of the HOX family, which regulates cell fate, early development patterns, and organogenesis (Shah and Sukumar, 2010; Rezsohazy et al., 2015). As the first HOX gene to be expressed in connection with gastrulation during embryogenesis, HOXA1 plays important roles in modulation of cell proliferation, metastasis, and invasion (Bitu et al., 2012; Zha et al., 2012; Wardwell-Ozgo et al., 2014; Taminiau et al., 2016). These diverse functional roles of HOXA1 appear to be at least partially related to its ability to influence key signaling pathways involved in regulating the cell cycle.

In addition to miRNAs, DNA methylation, a major component of the epigenome, is also a regulator of mammalian embryogenesis (Santos et al., 2002; Zhang et al., 2016). It was previously reported that there might be a possible synergy between miRNA and DNA methylation of cancer-related genes (Shivakumar et al., 2017). To be more specific, miRNAs regulate DNA methylation by modulating DNMTs or methylation-related proteins (Wang et al., 2017). DNA methylation involves the covalent addition of a methyl group to the 5-carbon position of cytosine by DNMTs and regulates gene transcription without changing the DNA sequence (Wu and Zhang, 2014). There are three major DNMTs: DNMT3a, DNMT3b, and DNMT1. DNMT3a and DNMT3b are de novo methyltransferases that establish the initial DNA methylation patterns, while DNMT1 is the maintenance DNA methyltransferase that is the most abundant DNMT in various cell types (Jeltsch, 2002; Jin and Robertson, 2013). DNA methylation plays important roles in mammalian development, $\mathrm{X}$ chromosome inactivation, genomic integrity, and genomic imprinting. Aberrant DNA methylation has been implicated in a lot of disease conditions, such as neurological disease, cancer, and cardiovascular diseases (Robertson, 2005; Kanai and Hirohashi, 2007; Stenvinkel et al., 2007; Bergman and Cedar, 2013). DNA methylation status has also been linked to cell apoptosis and cell proliferation (Wang et al., 2016; Loginov et al., 2017). However, possible mechanisms of synergistic interactions between miRNA and DNA methylation on transcriptomic changes in bovine embryos and its association with pregnancy outcome are so far unknown.

For this study, we hypothesized that miR-10b would exert its detrimental effect on embryo development through influencing DNA methylation and/or directly targeting certain genes such as HOXA1. To test this hypothesis, we supplemented culture medium with miR-10b mimics and microinjected siHOXA1 into embryos during in vitro bovine preimplantation embryo development and measured DNMTs mRNA levels.

\section{METHODS AND MATERIALS}

\section{Experiment Design}

In this study, miR-10b mimics were supplemented into presumed zygotes in vitro and embryos were cultured until day 8 . Blastocysts were evaluated by morphological assessment and apoptosis staining. RT-qPCR was performed to determine the uptake of mimics by embryos and the expression of DNMTs. HOXA1 was validated to be a direct target of miR-10b with dual-luciferase assay in embryos and MDBKs. To functionally study HOXA1, siHOXA1 was microinjected into presumed zygotes and embryos were cultured until day 8. Blastocysts were evaluated using similar parameters to miR-10b functional analysis. In addition, MDBKs were transfected with miR-10b mimics or siHOXA1. Cell viability and cell cycle were analyzed using WST-1 assay and PI staining.

\section{MiR-10b Mimics Supplementation}

All animal handlings were approved by the Ethical Committee of the Faculty of Veterinary Medicine (EC2013/118) of Ghent University. All methods were performed in accordance with the relevant guidelines and regulations. The rationale behind this experiment was to investigate whether miR-10b present in the culture medium can effectively be taken up by embryos and thus affect early embryo development. To this end, bovine embryos were produced according to the previously used routine in vitro fertilization (IVF) methods in our lab (Wydooghe et al., 2014). Briefly, to obtain cumulus oocyte complexes from 4- to 8-mm-diameter follicles, ovaries were collected from a slaughterhouse and aspirated with a needle and fluid was pooled. Cumulus oocyte complexes were then cultured in groups of 60 in 500- $\mu$ l maturation media-containing TCM199 (Life Technologies, Ghent, Belgium) supplemented with $20 \%$ heat-inactivated fetal bovine serum (FBS) (Biochrom AG, Berlin, Germany) at $38.5^{\circ} \mathrm{C}$ in $5 \% \mathrm{CO}_{2}$ in the air. After $22 \mathrm{~h}$, frozen-thawed bovine spermatozoa were separated using a Percoll gradient (GE Healthcare Biosciences, Uppsala, Sweden). The final sperm concentration for fertilization was $1 \times 10^{6} \mathrm{spermatozoa} / \mathrm{ml}$. After $21 \mathrm{~h}$, presumed zygotes were transferred to $50-\mu \mathrm{l}$ drops of synthetic oviductal fluid (SOF) supplemented with ITS $(5 \mu \mathrm{g} / \mathrm{ml}$ insulin $+5 \mu \mathrm{g} / \mathrm{ml}$ transferrin $+5 \mathrm{ng} / \mathrm{ml}$ selenium) and $4 \mathrm{mg} / \mathrm{ml} \mathrm{BSA}$. MiRNA mimics (double-stranded, chemically synthesized RNAs that mimic mature endogenous miR-10b) or control mimics (doublestranded, chemically synthesized RNAs that have no homology to any known microRNA or mRNA sequences) were purchased from Qiagen (Germantown, USA) and supplemented into the culture medium of presumed zygotes with a final concentration of $1 \mu \mathrm{M}$. Culture occurred in groups of 25 , covered with mineral oil at $38.5^{\circ} \mathrm{C}$ in $5 \% \mathrm{CO}_{2}, 5 \% \mathrm{O}_{2}$, and $90 \% \mathrm{~N}_{2}$. Embryo quality was assessed during development and all blastocysts (day 8) were collected for RNA and immunofluorescence analysis. 


\section{TUNEL Staining}

TUNEL staining was performed using a previously described protocol (Ortiz-Escribano et al., 2017) with a commercial in situ cell death detection kit (Sigma, St. Louis, USA). Blastocysts were fixed in neutral buffered $4 \%$ paraformaldehyde at room temperature (RT) for $1 \mathrm{~h}$, and then permeabilized with $0.1 \%$ Triton X-100 at RT for $10 \mathrm{~min}$. Afterwards, blastocysts were incubated with $20 \mu \mathrm{l}$ of TUNEL mixture for $1 \mathrm{~h}$ at $37^{\circ} \mathrm{C}$ and subsequently washed three times in phosphate-buffered saline (PBS) and finally stained with $10 \mu \mathrm{g} / \mathrm{ml}$ 4',6-diamidino-2-phenylindool (DAPI) for $10 \mathrm{~min}$. Slides were examined using a $20 \times$ water immersion objective on a Leica TCS-SP8 X confocal microscope (Leica Microsystems, Wetzlar, Germany). The apoptosis ratio was expressed as the total number of TUNEL-positive cells relative to the total number of the cells per blastocyst.

\section{Microinjection}

The microinjection was performed using the previously described protocol (Goossens et al., 2010; Vandenberghe et al., 2018). Briefly, bovine zygotes were produced in vitro and randomly divided into three groups: (Valadi et al., 2007) a control group of zygotes that was not manipulated (Donker et al., 2012), a test group of zygotes that were injected with the short-interfering RNA (siRNA) targeting HOXA1 (Luo et al., 2009), and zygotes injected with a non-target control siRNA (siNTC) (Qiagen, Germantown, USA). The injections were performed on an inverted microscope (Olympus, Tokyo, Japan) using piezo drill assisted micromanipulation (Narishige, London, UK). During injection, zygotes were kept at $38^{\circ} \mathrm{C}$ in 5 - $\mu$ l droplets of Hepesbuffered TCM-199 covered with mineral oil. Ten picoliters of siRNA $(20 \mu \mathrm{M})$ was injected into the cytoplasm of zygotes $21 \mathrm{~h}$ post insemination (hpi). Subsequently, zygotes were washed with SOF and then cultured in groups of 25 in 50- $\mu$ l droplets of SOF covered with mineral oil at $38.5^{\circ} \mathrm{C}$ in $5 \% \mathrm{CO}_{2}, 5 \% \mathrm{O}_{2}$, and $90 \% \mathrm{~N}_{2}$. Embryo survival was checked after injection, and the cleavage rate (48 hpi) and the percentage of blastocysts [ 8 days post insemination (dpi)] were determined. Blastocysts were collected for RNA and for immunofluorescence analysis. Three replicates ( $n=25$ each) were performed.

\section{RNA Isolation and RT-qPCR}

The expression patterns of HOXA1 and DNMTs were analyzed using RT-qPCR. Total RNA was isolated from three pools of five blastocysts each using the RNeasy Micro kit (Qiagen, Germantown, USA) and reverse transcribed using the iScript cDNA synthesis kit (BioRad, Brussels, Belgium). RT-qPCR was performed on a BioRad CFX 96 PCR detection system by mixing $2.5 \mu \mathrm{l}$ of template cDNA with $5 \mu \mathrm{l}$ of Sso Advanced SYBR Green Supermix (BioRad, Brussels, Belgium) and $300 \mathrm{nM}$ of each primer in a $10-\mu \mathrm{l}$ total volume. The PCR program consisted of an initial denaturation step at $95^{\circ} \mathrm{C}$ for $3 \mathrm{~min}$, followed by 40 cycles of denaturation at $95^{\circ} \mathrm{C}$ for $5 \mathrm{~s}$ and a combined primer annealingextension step at specific primer annealing temperatures for $30 \mathrm{~s}$. A melting curve was produced afterwards by heating samples from $70^{\circ} \mathrm{C}$ to $95^{\circ} \mathrm{C}$ in $0.5^{\circ} \mathrm{C}$ increments for $5 \mathrm{~s}$ to confirm a single specific peak for each pair of primers (Supplementary Table S1).
GAPDH and YWHAZ, previously shown to be stable in bovine embryos (Goossens et al., 2005), were quantified to normalize mRNA expression levels using geNorm (Vandesompele et al., 2002). RT-qPCR reactions were performed in triplicate, and the $2^{-\Delta \Delta C t}$ method was used to analyze the data. The primer sequences used for RT-qPCR are listed in Supplementary Table S1.

The expression pattern of miR-10b was analyzed using RT-qPCR. MiRNA was isolated from three pools of five blastocysts each using the miRNeasy Mini kit (Qiagen, Germantown, USA) and reverse transcribed using a miScript II RT kit (Qiagen, Germantown, USA). The miRNA levels were quantified with a miScript SYBR Green Kit containing $10 \times$ miScript Universal Primer (Qiagen, Germantown, USA). The RT-qPCR was performed by mixing $1 \mu \mathrm{l}$ of template cDNA with $5 \mu$ of $2 \times$ QuantiTect SYBR Green PCR Master Mix (Qiagen, Germantown, USA), $10 \times$ miScript Primer assay, and $10 \times$ miScript Universal Primer in $10 \mu \mathrm{l}$ of final volume. The PCR program consisted of an initial denaturation step at $95^{\circ} \mathrm{C}$ for $15 \mathrm{~min}$, followed by 40 cycles of denaturation at $94^{\circ} \mathrm{C}$ for $15 \mathrm{~s}$, a combined primer annealing-extension step at specific primer annealing temperatures for $30 \mathrm{~s}$ and then at $70^{\circ} \mathrm{C}$ for $30 \mathrm{~s}$. A melting curve was produced afterwards by heating samples from $70^{\circ} \mathrm{C}$ to $95^{\circ} \mathrm{C}$ in $0.5^{\circ} \mathrm{C}$ increments for $5 \mathrm{~s}$ to confirm a single specific peak for each pair of primers. U6 (Mondou et al., 2012; Abd El Naby et al., 2013) and SNORD61 (Qiagen, Germantown, USA), previously shown to be stable in bovine embryos, were quantified to normalized mRNA expression levels using geNorm (Vandesompele et al., 2002).

\section{Cell Culture and Transfection}

HEK293Ts or MDBKs were thawed and resuspended in Dulbecco Modified Eagle Media (DMEM) (Thermo Fisher Scientific, Waltham, USA) containing penicillin/streptomycin (100 U/ml) and 10\% FBS (VWR, Radnor, USA). Culture occurred at $37^{\circ} \mathrm{C}, 5 \% \mathrm{CO}_{2}$ in an incubator. MiR-10b mimics or control mimics were delivered into MDBKs using Hiperfect reagent (Qiagen, Germantown, USA) in Opti-MEM media (with a final concentration of $50 \mathrm{nM}$ ). SiRNA or siNTC was transfected into MDBKs using Lipofectamine 2000 (Invitrogen, Carlsbad, USA) according to the manufacturer's instructions (with a final concentration of $500 \mathrm{nM}$ ). Twenty-four or $48 \mathrm{~h}$ after transfection, total RNA or protein was extracted for RT-qPCR or Western blotting (WB).

\section{Validation of HOXA1 as a Target of miR-10b}

To understand the mechanisms by which miR-10b induces apoptosis of embryonic cells, we used three computational algorithms, Targetscan, PicTar, and Miranda, to identify putative miR-10b targets in cattle. If a target was identified by all three algorithms, it was considered likely to be a miRNA target. Of the putative target genes identified in this way, HOXA1 was chosen for further analysis because it was previously shown to be implicated in cell proliferation in human epithelial cells (Bitu et al., 2012) and cell growth, invasion, and migration in esophageal cancer cells (Li et al., 2017), which makes it of particular interest. The 
wild-type 3'UTR of HOXA1 (594 bp) (NC_037331.1) containing the predicted miR-10b binding site was amplified and ligated into the psiCHECK2 vector (Promega, Madison, USA) via NotI and XhoI sites and subsequently confirmed by sequencing. To test whether the predicted miR-10b target site in the HOXA1 $3^{\prime} \mathrm{UTR}$ is critical for the miR-10b-mediated repression of HOXA1 expression, the seed sequence of the predicted miR-10b's binding site was mutated. The primer sequences used for vector construction are listed in Supplementary Table S1.

HEK293T cells (70-80\% confluency) were co-transfected with $500 \mathrm{ng}$ of plasmid harboring wild-type or mutant sequences of the $3^{\prime} \mathrm{UTR}$ of HOXA1 and $5 \mathrm{nM}$ miR-10b mimics/control mimics using Lipofectamine 2000 in Opti-MEM media. Transfected cells were collected $24 \mathrm{~h}$ post-transfection and assayed using the Dual Luciferase reporter Kit (Promega, Madison, USA).

\section{Protein Isolation and Western Blot}

Western blot was carried out using standard methods. Briefly, total protein was extracted from cultured cells $48 \mathrm{~h}$ after transfection using radioimmunoprecipitation lysis buffer consisting of $50 \mathrm{mM}$ Tris- $\mathrm{HCl}$ ( $\mathrm{pH} 7.5$ ), 1\% NP-40, 0.1\% SDS, $0.5 \%$ sodium deoxycholate, $150 \mathrm{mM} \mathrm{NaCl}$, and protease inhibitors. Before being loaded onto $10 \%$ SDS-polyacrylamide gels, the samples were denatured for $10 \mathrm{~min}$ at $100^{\circ} \mathrm{C}$. Separated proteins were then transferred onto nitrocellulose membranes and subsequently blocked overnight with 5\% non-fat milk in PBS with $0.1 \%$ Tween-20. Afterwards, membranes were incubated overnight with 1/1,000 rabbit anti-HOXA1 (Novus Biologicals, Abingdon, UK) or $1 / 1,000$ rabbit anti- $\beta$-actin. After three washes, the membranes were incubated with HRP-conjugated goat antirabbit $\operatorname{IgG}(\mathrm{H}+\mathrm{L})$ at room temperature for $2 \mathrm{~h}$. Signals were detected by autograph using SuperSignal West Femto Maximum Sensitivity Substrate (Thermo Fisher Scientific, Waltham, USA).

\section{Cell Cycle Assays: PI Staining and Flow Cytometry}

Forty-eight hours after transfection, MDBKs were collected by centrifugation, followed by fixation in ice-cold $70 \%$ ethanol at $4{ }^{\circ} \mathrm{C}$ overnight. Then, the cells were stained with a final concentration of $50 \mu \mathrm{g} / \mathrm{ml}$ propidium iodide PI and $100 \mu \mathrm{g} / \mathrm{ml}$ RNase A in PBS. After $30 \mathrm{~min}$ in the dark, the stained cells were analyzed using Accuri ${ }^{\mathrm{TM}}$ C6 flow cytometry (BD, Erembodegem, Belgium).

\section{Cell Viability Assays: WST-1 Colorimetric Assay}

Cell viability was determined using the WST-1(4-(3-(4iodophenyl)-2-(4-nitrophenyl)-2H-5-tetrazolio)-1,3-benzene disulfonate) (Merck, Kenilworth, USA). The assay was performed with $\sim 20,000$ cells using 96-well plates. Fortyeight hours after transfection, $10 \mu \mathrm{l}$ of WST-1 was added to $90-\mu \mathrm{l}$ samples. The samples were then measured at $450 \mathrm{~nm}$ wavelength (570 $\mathrm{nm}$ as a reference wavelength) on an EZ read 400 microplate reader (Biochrom, Holliston, USA). After background subtraction, the viability was determined by comparing the absorbance values of samples.

\section{STATISTICAL ANALYSIS}

The statistical analyses were performed using Student's $t$ test or ANOVA followed by Tukey's test using GraphPad prism version 5. For each analysis, $P<0.05$ was considered significant. The data are presented as mean \pm S.D. and derived from at least three independent experiments.

\section{RESULTS}

\section{MiR-10b Mimics Can Be Taken Up by Bovine Embryos and Increase Apoptosis of Embryonic Cells}

RT-qPCR results showed that miR-10b is indeed taken up by the embryos as its levels were noticeably higher (approximately 70 times) in the miR-10b mimics supplemented group compared with the control mimics group (Figure 1A). No significant difference was found in cleavage or blastocyst rate between the miR-10b mimics group and the control mimics group (Figures 1B, C). However, TUNEL staining showed a higher apoptosis rate in the miR-10b mimics group (10.52\%) than in the control mimics group (4.88\%) (Figures 1D, E).

\section{MiR-10b Regulates the Expression of HOXA1 Protein}

The HOXA1-encoded mRNA contains a 3'UTR element that is complementary to the miR-10b seed sequence (Figure 2A). To evaluate whether miR-10b directly targets $H O X A 1$, we constructed luciferase reporter plasmids with wild-type (psiCHECK2-HOXA1-WT-3'UTR) and a mutated 3'UTR (psiCHECK2-HOXA1-MUT-3'UTR). After co-transfecting the reporters with miR-10b mimics into HEK293T cells, we observed a clear reduction in the activity of the luciferase reporter gene fused to the wild-type HOXA1 3'UTR $(63.5 \%$ reduction, Figure 2B).

After miR-10b mimics supplementation into embryo culture medium, no significant mRNA difference could be observed (Figure 2C), but a reduction of the endogenous HOXA1 protein was clear (Figure 2D). This indicates that miR-10b directly targets HOXA1 and inhibits translation of the mRNA.

Since further functional analysis of miR-10b and HOXA1 was out of practical necessity, performed using a bovine cell line (MDBK), the direct relationship between miR-10b and HOXA1 was also analyzed on MDBKs. MiR-10b mimics were delivered into MDBKs with Lipofectamine 2000 and the expression of HOXA1 was examined using RT-qPCR and WB. No significant differences were found at the mRNA level (Figure 2E), while HOXA1 protein levels were reduced in the miR-10b mimics group compared with the control mimics group (Figure $2 \mathbf{F}$ ), in agreement with the results obtained on embryos. Other potential targets of miR-10b are listed in Supplementary Table S2. Among these potential target genes, HOXD10 has been already proven to be a direct target of $\mathrm{miR}-10 \mathrm{~b}$ and regulates cell proliferation in human glioblastoma cells and hepatocellular carcinoma cells (Su et al., 2001; Chisaka and Kameda, 2005). 

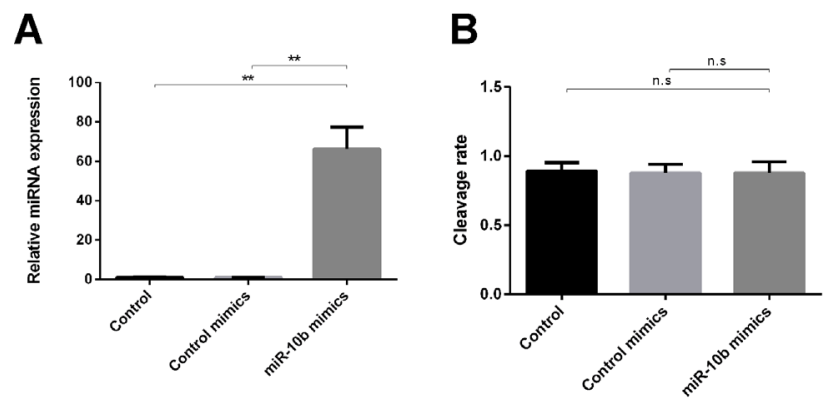

D

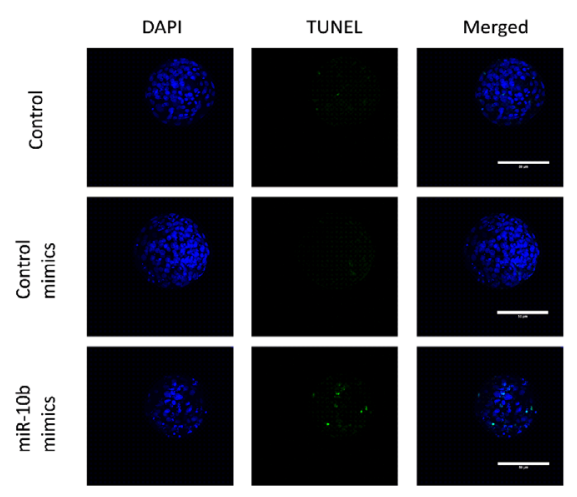

C

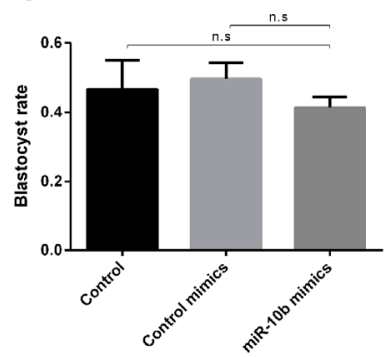

$\mathbf{E}$

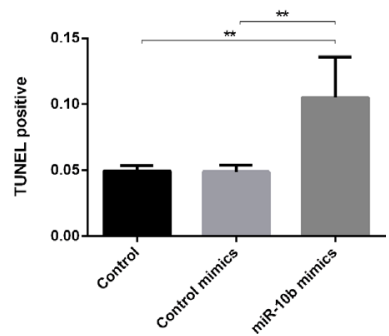

FIGURE 1 | Effects of miR-10b mimics on embryo growth and apoptosis. (A) Embryos were treated with miR-10b mimics and the relative expression level of miR-10b was detected using RT-qPCR at 8 dpi. (B and C) Cleavage and blastocyst rate of embryos treated with miRNA mimics or control mimics were assessed. (D and E) Apoptosis rate of embryos was determined by TUNEL staining. The statistical analyses were performed using one-way ANOVA and data are presented as mean $\pm \mathrm{SD}$ of three experiments $\left({ }^{\star *} P<0.01\right.$; ns, no significance).

HOXA3, another member of the HOX family, was reported to regulate cell proliferation in mouse thymic epithelial cells and neural crest cells (Su et al., 2001; Chisaka and Kameda, 2005) and differentiation in human hematopoietic progenitor cells (Mahdipour et al., 2011).

\section{MiR-10b Mimics Result in Aberrant DNMTs Expression in Bovine Embryos}

Recent studies have shown that epigenetic changes such as DNA methylation and miRNAs play crucial roles in embryonic development (Greenberg et al., 2016; Liu et al., 2016; Okada and Yamaguchi, 2017). However, the interaction mechanisms between miRNAs and DNA methylation have remained largely unexplored. In this study, we examined expression of DNMTs after supplementation of miR-10b mimics into embryo culture media. The expression of DNMT1 was significantly lower in the miR-10b mimics-treated group compared with the control mimics group, while DNMT3b expression was significantly higher in the miR-10b mimics group compared with the control mimics group. No significant differences were found in DNMT3a for embryos cultured with miR-10b mimics versus control mimics (Figure 3).

\section{Microinjection of siHOXA1 Increases Apoptosis of Embryonic Cells and Downregulates DNMTs in Bovine Embryos}

To investigate the possible mechanisms of HOXA1's function on embryos, blastocyst formation was determined and the expression of DNMTs in embryos was validated after siHOXA1 microinjection. As presented in Figure $\mathbf{4 A}$, the cleavage rate showed no significant difference between the siHOXA1-injected group and the siNTC-injected group, while the blastocyst rate was decreased in the siHOXA1-injected group compared with the siNTC-injected group, but the change did not reach statistical significance (Figure 4B). TUNEL staining showed that the apoptosis rate in the siHOXA1-injected group was $18.06 \%$, while it was $4.07 \%$ in the siNTC-injected group (Figures 4C, D), meaning that the injection of siHOXA1 increased apoptosis of embryonic cells.

We also examined expression of HOXA1 mRNA and DNMTs mRNA after injecting siHOXA1 into embryos. The expression of HOXA1 was 10.8 times lower in the siHOXA1-injected group than in the siNTC-injected group (Figure 4E). The expression of DNMT1 (5.2 times), DNMT3a (8.7 times), and DNMT3b (5.2 times) was found to be significantly decreased in the siHOXA1 injected group compared to the siNTC group (Figure 4E). 
A

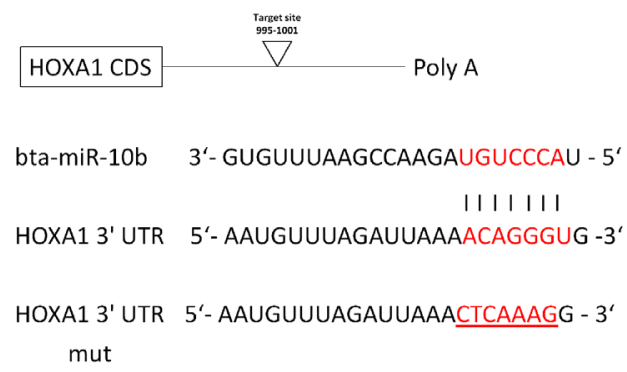

C

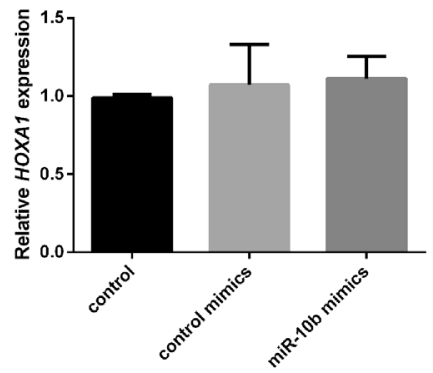

E

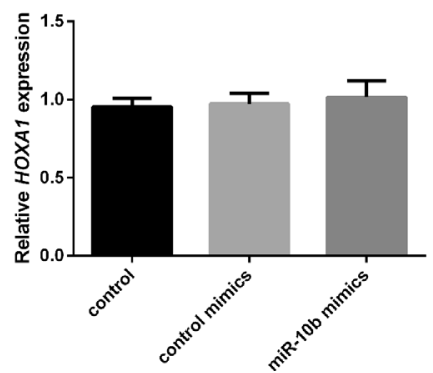

B

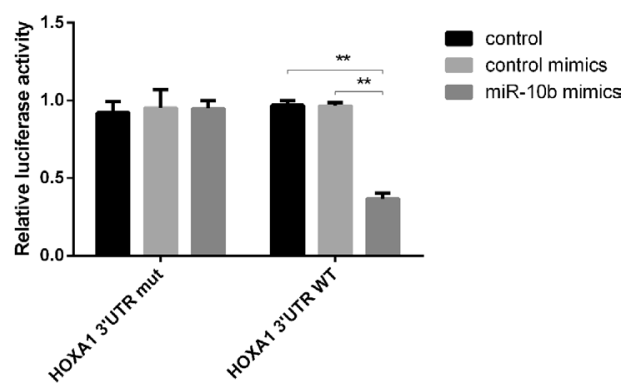

D

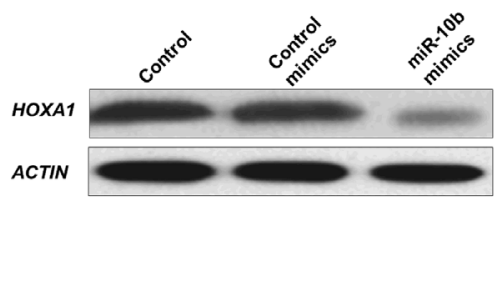

$\mathbf{F}$

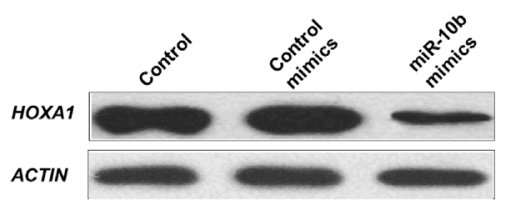

FIGURE 2 | HOXA1 is a direct target of miR-10b. (A) 3'UTR analysis of HOXA1 containing putative regions that match the seed sequence of miR-10b, and the mutated nucleotides are underlined. (B) Overexpression of miR-10b inhibited Renilla luciferase activities. HEK-293T cells were cotransfected with 500 ng of reporter plasmid containing the MUT or WT-type UTRs and $5 \mathrm{nM}$ miR-10b mimics. After $24 \mathrm{~h}$, Renilla luciferase was normalized against firefly luciferase and then presented. (C and D) Embryos were treated with miR-10b mimics or control mimics and the relative levels of HOXA1 were detected with RT-qPCR and WB. (E and F) MiR-10b mimics were transfected into MDBKs. After $48 \mathrm{~h}$ or $24 \mathrm{~h}$, cells were harvested for RT-qPCR or WB. The statistical analyses were performed using ANOVA and data are presented as mean \pm SD of three experiments $\left({ }^{* *} P<0.01\right)$.

\section{MiR-10b Overexpression and HOXA1 Knockdown in MDBKs Decrease Cell Viability}

Although miR-10b has been shown to regulate cell progression in human and mouse, the regulatory relationship is still unclear in bovine. To further verify the above results, we explored the effect of miR-10b overexpression and HOXA1 knockdown on cell progression using the bovine cell line MDBK. MDBKs were transfected with miR-10b mimics or siHOXA1, and their expression was assessed using RT-qPCR. As presented in Figures 5A, B, the expression of miR-10b was successfully increased in MDBKs by delivery of miR-10b mimics and HOXA1 expression was significantly knocked down in MDBKs by transfection with SiHOXA1.

The cellular metabolic activity, which indicates cell viability, was monitored using the WST-1 assay. As shown in Figure 5C, cell viability was reduced in miR-10b mimics-delivered cells (28\%) compared with control mimics-delivered cells. Similarly, the inhibition of HOXA1 significantly decreased the cell viability (34\%). 


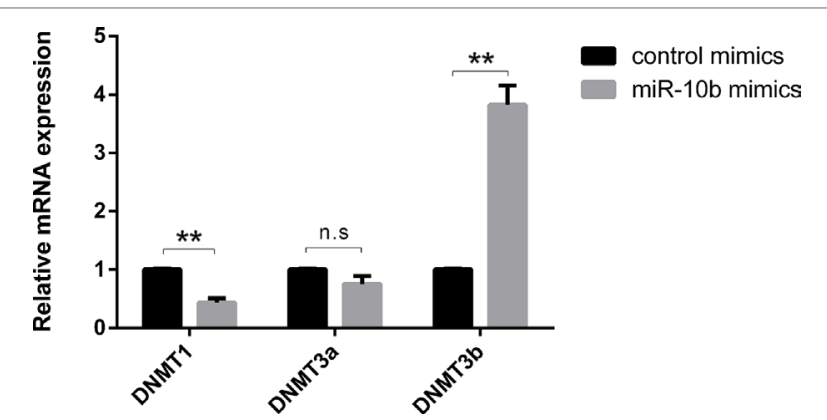

FIGURE 3 | Effects of miR-10b mimics on DNMTs expression. Embryos were treated with miR-10b mimics and the relative expression levels of DNMTs were detected using RT-qPCR at $8 \mathrm{dpi}$. The statistical analyses were performed using two-way ANOVA, and data are presented as mean $\pm \mathrm{SD}$ of three experiments ( ${ }^{\star \star} P<0.01$; ns, no significance).

\section{MiR-10b Overexpression and HOXA1 Knockdown in MDBKs Slow Down the Cell Cycle}

To elucidate the mechanism of growth inhibition by miR-10b overexpression and HOXA1 downregulation, flow cytometry was used to analyze the cell cycle in MDBKs. The intensity of
PI staining has a positive correlation with the number of cells. A higher proportion of cells in G1 indicates the slowing down of the cell cycle, while a higher proportion of cells in G2 and S stages indicates the promoting of the cell cycle. As shown in Figure 5D, cell cycle phase displayed a $7.66 \%$ increase of treated cells in the G1 phase and an $8.13 \%$ decrease in the $S$ phase after the delivery of miR-10b mimics, indicating cell growth suppression. Similarly, knockdown of HOXA1 resulted in a $10.86 \%$ increase in cell number in the G1 phase and an $11.48 \%$ decrease in the $\mathrm{S}$ phase compared with the siNTC-transfected group.

\section{DISCUSSION}

In our previous study (Lin et al., 2019), we have reported that several miRNAs were differentially released into conditioned media from bovine embryos with different developmental competence. One of those, miR-10b, was previously shown to be expressed in bovine embryos (Goossens et al., 2013), oocytes (Abd El Naby et al., 2013), follicles, and ovarian tissues (Huang et al., 2011; Gebremedhn et al., 2015). Several studies have shown that miR-10b plays important roles in cell apoptosis, cell proliferation, cell migration, and invasion in
A

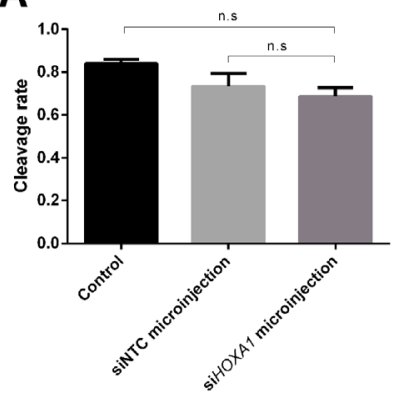

D

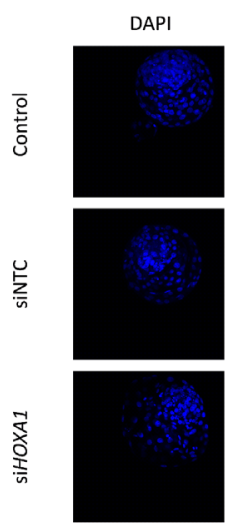

B

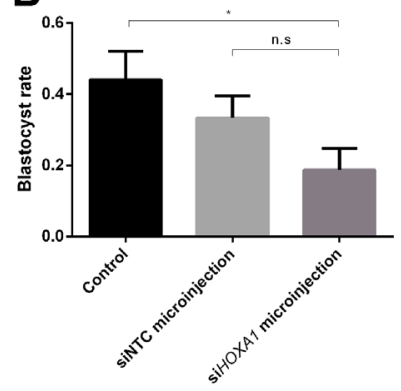

E
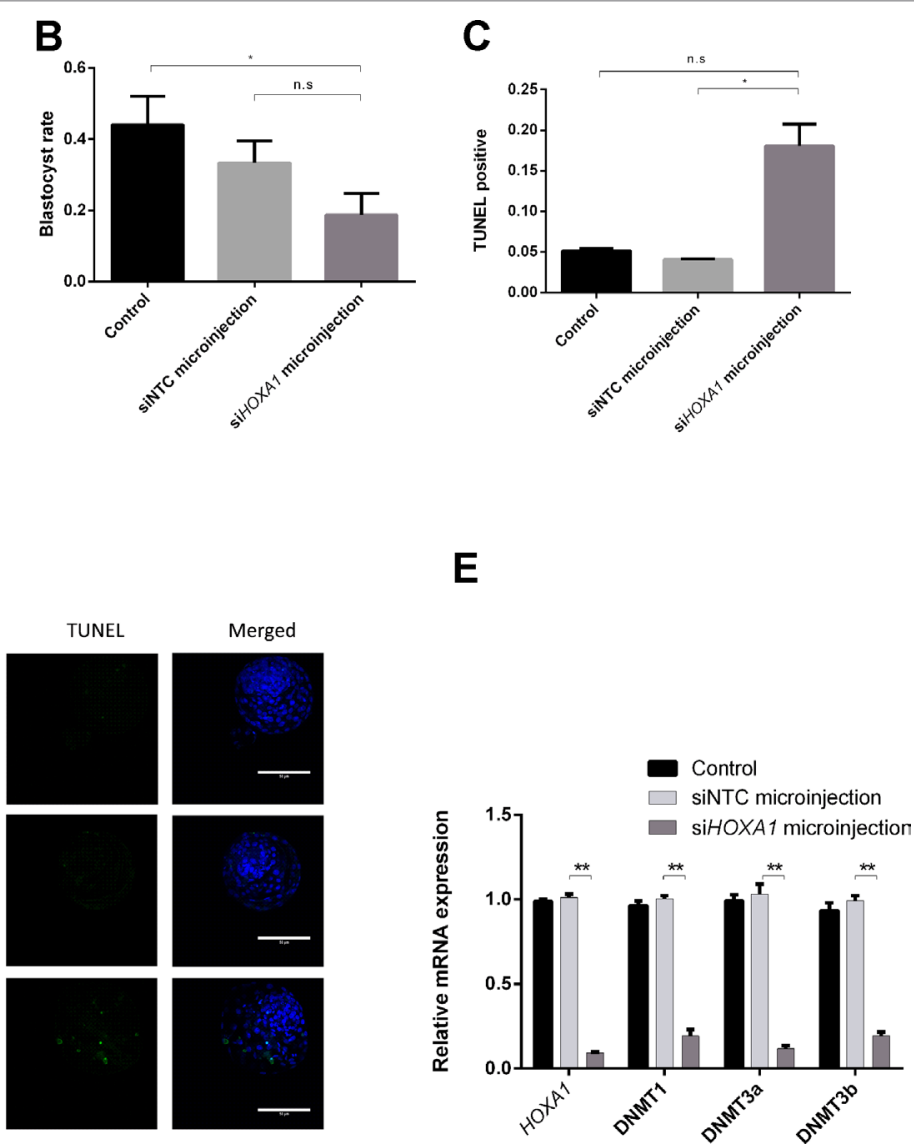

FIGURE 4 | Effects of HOXA1 in embryo growth, apoptosis, and DNMTs. Embryos were injected with siHOXA1 and the cleavage rate (A) and blastocyst rate were assessed (B); cell apoptosis was determined by TUNEL staining (C and D); HOXA1 and DNMTs expressions were evaluated using RT-qPCR (E). The statistical analyses were performed using ANOVA and data are presented as mean $\pm \mathrm{SD}$ of three experiments $\left({ }^{\star} P<0.05\right.$, ${ }^{\star \star} P<0.01$; ns, no significance). 
A

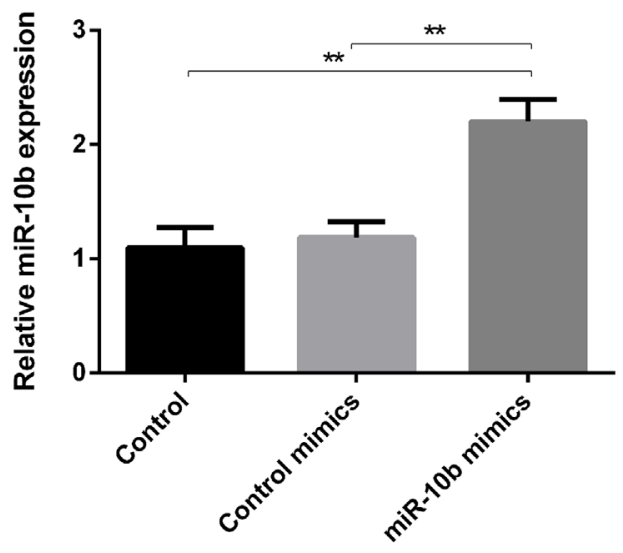

C

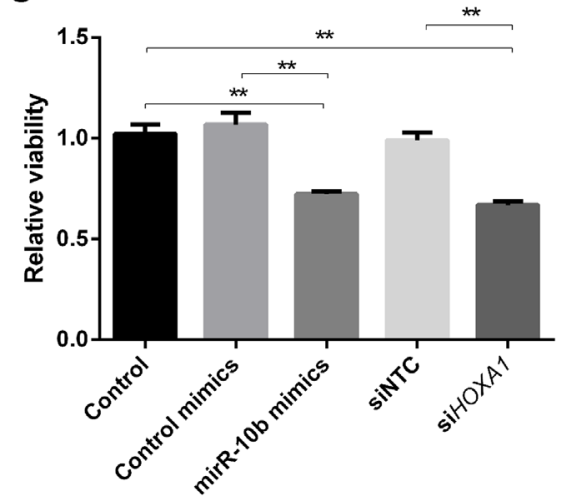

B

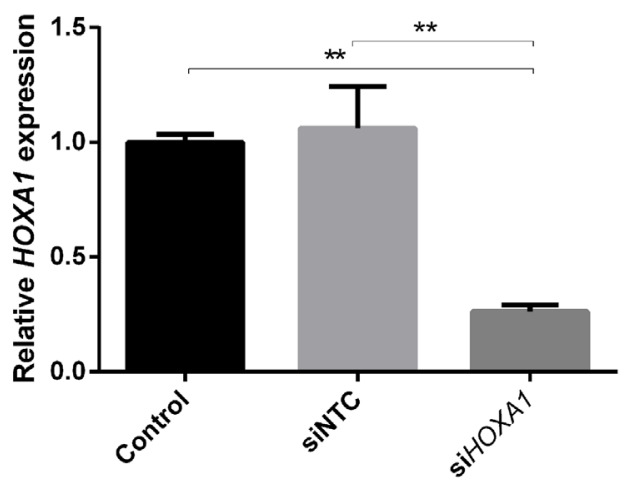

D

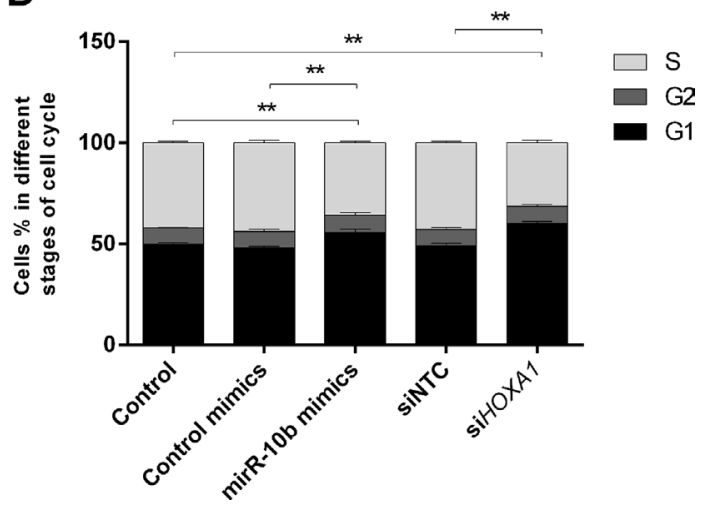

FIGURE 5 | Effects of miR-10b overexpression and HOXA1 knockdown on cell progression. (A and $\mathbf{B})$ MDBKs were reverse transfected with miR-10b mimics or siHOXA1 for $48 \mathrm{~h}$. RT-qPCR was then performed to assess the expression of miR-10b and HOXA1. (C and D) MDBKs were reverse transfected with miR-10b mimics or siHOXA1 for $48 \mathrm{~h}$. (C) Cell viability was measured using the WST-1 assay, and (D) cell cycle assay by PI staining. Data are presented as mean \pm SD of three experiments $\left({ }^{\star \star} P<0.01\right)$.

human cancer cells (Wang et al., 2007; Liao et al., 2014; Chen et al., 2016; Zhen et al., 2016; Zhu et al., 2016; Guan et al., 2018), mouse cells (Tan et al., 2018), and goat granulosa cells (Peng et al., 2016).

To further investigate how miR-10b negatively impacts bovine preimplantation bovine quality, we tested two possible mechanisms based on target gene prediction and literature.

Firstly, we tested HOXA1 and verified it as a direct target of miR-10b. As one of the HOX family members, HOXA1 is involved in various biological processes, including cell apoptosis and growth (Zhang et al., 2018). For instance, it was demonstrated that HOXA1 can inhibit the migration, invasion and growth of HepG2 cells (Zha et al., 2012). Besides, forced expression of HOXA1 in human mammary carcinoma cells resulted in increased proliferation and decreased apoptotic cell death in a Bcl2-dependent manner (Zhang et al., 2003). In addition, HOXA1 was found to enhance cell invasion, proliferation, and metastasis of prostate cancer cells (Wang et al., 2015). By microinjecting siHOXA1 into zygotes, we found increased apoptosis in bovine embryos, an effect similar to after adding miR-10b mimics. The combination of these results with the observation that the HOXA1 protein level was decreased after supplementing miR$10 \mathrm{~b}$ mimics into culture medium of embryos gives an indication that miR-10b might induce apoptosis of embryonic cells via targeting HOXA1. This could be in a Bcl-2-dependent manner as mentioned above, or through regulating other proteins involved 
in the apoptotic process, such as Bax, Bak, Bcl-xL, Fas, and FADD (Zhang et al., 2003).

Secondly, we tested if miR-10b exerts its negative effect on embryo development by interacting with the DNA methylation status. Since DNMTs are known to be involved in the maintenance of methylation patterns of genes (DNMT1) and de novo methylation (DNMT3a and DNMT3b), we investigated the mRNA levels of all three members after miR-10b mimics supplementation in culture medium. This resulted in a decrease in DNMT1 expression, an increase of DNMT3b expression, and no effect on DNMT3a. The maintenance of methylation and de novo methylation are two distinct processes that are required for the establishment and mitotic inheritance of tissuespecific methylation patterns. DNMT1 is recognized as the maintenance DNMT that copies methylation patterns after DNA replication as it has a preference for hemimethylated, rather than unmethylated DNA (Talbot et al., 1997). Loss of Dnmt1 in mice has been reported to cause global DNA methylation loss and embryonic death (Tsumura et al., 2006). Moreover, loss of DNMT1 in human colon cancer cell lines contributes to growth impairment (Rhee et al., 2002). DNMT3b is essential for early embryonic development and responsible for de novo methylation (Watanabe et al., 2002; Uysal et al., 2017). In fact, overexpression of DNMT3b was shown to result in aberrant DNA methylation in T-cell acute lymphoblastic leukemia (Poole et al., 2017) and to be significantly correlated with unfavorable prognosis in various human malignancies (Kim et al., 2006; Park et al., 2006; Vallböhmer et al., 2006; Wang et al., 2006; Lin et al., 2007; Xing et al., 2008).

Our data indicate an interaction between miRNA expression and DNA methylation, which is in agreement with other studies (Kim et al., 2014; Shivakumar et al., 2017; Wang et al., 2017). Taken together, the DNMT1 downregulation and DNMT3b overexpression after overexpressing miR-10b found in the present study points to a link between aberrant DNA methylation and hampered development in bovine embryos. To our knowledge, this is the first study focusing on miRNAs regulation of DNA methylation in bovine embryos.

Since our results outlined above showed that miR-10b regulates both HOXA1 and DNMTs, we further investigated the possible relationship between HOXA1 and DNA methylation. Microinjection of siHOXA1 clearly downregulated all three $D N M T s$, indicating that miR-10b may exert its inhibitory effect on DNMT1 by regulating HOXA1, as DNMT1 mRNA has no binding site for miR-10b (according to three computational methods: Targetscan, PicTar and Miranda) and hence is not a direct target of miR-10b. In a similar way, DNMT3b mRNA also has no binding site for miR-10b, which indicates that the upregulation of DNMT3b by miR-10b could be an indirect effect mediated by one or multiple other targets of miR-10b. Moreover, miR-10b overexpression and HOXA1 knockdown resulted in aberrant DNMT expression and an increased embryo apoptosis ratio. Previous findings in human cancer cells have shown that cell apoptosis and cell proliferation are related to DNA methylation, and DNA methylation can help inactivate apoptotic pathways at several points (Cho et al., 2011; Ye et al., 2016; Costa et al., 2017; Loginov et al., 2017).
Considering the fact that the compaction of embryos makes it difficult to use them for flow cytometry analysis, a complementary study regarding the effect of miR-10b overexpression and HOXA1 knockdown on cell cycle was performed using the bovine cell line MDBK. The delivery of miR-10b mimics to MDBKs resulted in reduced cell viability and a high proportion at G1 stage. Similarly, the transfection of siHOXA1 also led to reduced cell viability and a high proportion at G1 stage, indicating that miR-10b suppresses cell growth by targeting HOXA1 and thus complementing the results obtained in the embryos.

Given the above results, bovine embryo-secreted miR$10 \mathrm{~b}$ can be regarded as a potential biomarker for suppressed preimplantation developmental competence. miRNAs are gaining interest as potential biomarkers for diseases (Mitchell et al., 2008; Qu et al., 2017; Ma, 2018), embryo development in cattle (Kropp and Khatib, 2015), and embryo viability in human (Rosenbluth et al., 2014). According to the majority of studies, miRNAs are stable biomarkers. For instance, it was shown that miRNA levels remain remarkably stable when plasma is freeze-thawed multiple times or subjected to prolonged room temperature incubation (Mitchell et al., 2008). Besides, it was reported that miRNAs were stable frozen or refrigerated for $72 \mathrm{~h}$ and at room temperature for $24 \mathrm{~h}$ (McDonald et al., 2011). Apart from the stability, a biomarker should be easily detected. We have found miR-10b to be significantly higher expressed in the conditioned media of degenerate embryos compared to blastocysts in a previous study (Lin et al., 2019).

In this study, we examined the effects of embryo-secreted miR-10b on apoptosis and DNA methylation in bovine embryos. We conclude that miR-10b enhances apoptosis of embryonic cells via targeting HOXA1. Additionally, we found aberrant DNMTs expression after miR-10b mimics supplementation into embryo culture medium. As DNMTs are not direct targets of miR-10b, it probably exerts its effect on these genes through a network of other genes, among which is HOXA1.

\section{DATA AVAILABILITY}

All data generated or analyzed during this study are included in this published article and its Supplementary Information file.

\section{ETHICS STATEMENT}

All animal handlings were approved by the Ethical Committee of the Faculty of Veterinary Medicine (EC2013/118) of Ghent University. All methods were performed in accordance with the relevant guidelines and regulations.

\section{AUTHOR CONTRIBUTIONS}

XL performed the experiment and wrote the manuscript. KP helped to produce and stain embryos. KS contributed to the microinjection experiments. DD, BH, AS, and LP participated in the study design. All authors reviewed the manuscript. 


\section{ACKNOWLEDGMENTS}

This work was supported by Ghent University (BOF GOA project 01G01112). The authors thank Petra Van Damme for her excellent technical assistance.

\section{REFERENCES}

Abd El Naby, W. S., Hagos, T. H., Hossain, M. M., Salilew-Wondim, D., Gad, A. Y., Rings, F., et al. (2013). Expression analysis of regulatory microRNAs in bovine cumulus oocyte complex and preimplantation embryos. Zygote 21, 31-51. doi: $10.1017 /$ S0967199411000566

Bergman, Y., and Cedar, H. (2013). DNA methylation dynamics in health and disease. Nat. Struct. Mol. Biol. 20, 274. doi: 10.1038/nsmb.2518

Bitu, C. C., Destro, M. F., Carrera, M., da Silva, S. D., et al. (2012). HOXA1 is overexpressed in oral squamous cell carcinomas and its expression is correlated with poor prognosis. BMC Cancer 12, 146. doi: 10.1186/1471-2407-12-146

Chen, H., Fan, Y., Xu, W., Chen, J., Xu, C., Wei, X., et al. (2016). miR-10b inhibits apoptosis and promotes proliferation and invasion of endometrial cancer cells via targeting HOXB3. Cancer Biother. Radiopharm. 31, 225-231. doi: 10.1089/ cbr.2016.1998

Chisaka, O., and Kameda, Y. (2005). Hoxa3 regulates the proliferation and differentiation of the third pharyngeal arch mesenchyme in mice. Cell Tissue Res. 320, 77. doi: 10.1007/s00441-004-1042-z

Cho, H.-S., Kelly, J. D., Hayami, S., Toyokawa, G., Takawa, M., Yoshimatsu, M., et al. (2011). Enhanced expression of EHMT2 is involved in the proliferation of cancer cells through negative regulation of SIAH1. Neoplasia 13, 676-IN10. doi: $10.1593 /$ neo. 11512

Costa, S. F. S., Pereira, N. B., Pereira, K. M. A., Campos, K., de Castro, W. H., Diniz, M. G., et al. (2017). DNA methylation pattern of apoptosis-related genes in ameloblastoma. Oral Dis. 23, 779-783. doi: 10.1111/odi.12661

Donker, R. B., Mouillet, J. F., Chu, T., Hubel, C. A., Stolz, D. B., Morelli, A. E., et al. (2012). The expression profile of C19MC microRNAs in primary human trophoblast cells and exosomes. Mol. Hum Reprod. 18, 417-424. doi: 10.1093/ molehr/gas013

Gebremedhn, S., Salilew-Wondim, D., Ahmad, I., Sahadevan, S., Hossain, M. M., Hoelker, M., et al. (2015). MicroRNA expression profile in bovine granulosa cells of preovulatory dominant and subordinate follicles during the late follicular phase of the estrous cycle. PLOS One 10, e0125912. doi: 10.1371/ journal.pone.0125912

Goossens, K., Van Poucke, M., Van Soom, A., Vandesompele, J., Van Zeveren, A., and Peelman, L. J. (2005). Selection of reference genes for quantitative realtime PCR in bovine preimplantation embryos. BMC Dev. Biol. 5, 27. doi: 10.1186/1471-213X-5-27

Goossens, K., Mestdagh, P., Lefever, S., Van Poucke, M., Van Zeveren, A., Van Soom, A., et al. (2013). Regulatory microRNA network identification in bovine blastocyst development. Stem Cells Dev. 22, 1907-1920. doi: 10.1089/ scd.2012.0708

Goossens, K., Tesfaye, D., Rings, F., Schellander, K., Holker, M., Van Poucke, M., et al. (2010). Suppression of keratin 18 gene expression in bovine blastocysts by RNA interference. Reprod. Fer. Develop 22, 395-404. doi: 10.1071/ RD09080

Greenberg, M. V. C., Glaser, J., Borsos, M., Marjou, F. E., Walter, M., Teissandier, A., et al. (2016). Transient transcription in the early embryo sets an epigenetic state that programs postnatal growth. Nat. Genet. 49, 110. doi: 10.1038/ng.3718

Guan, L., Ji, D., Liang, N., Li, S., and Sun, B. (2018). Up-regulation of miR-10b-3p promotes the progression of hepatocellular carcinoma cells via targeting CMTM5. J. Cell. Mol. Med. 22, 3434-3441. doi: 10.1111/jcmm.13620

Homer, H., Rice, G. E., and Salomon, C. (2017). Review: embryo- and endometrium-derived exosomes and their potential role in assisted reproductive treatments-Liquid biopsies for endometrial receptivity. Placenta 54, 89-94. doi: 10.1016/j.placenta.2016.12.011

Huang, J., Ju, Z., Li, Q., Hou, Q., Wang, C., Li, J., et al. (2011). Solexa sequencing of novel and differentially expressed microRNAs in testicular and ovarian tissues in Holstein cattle. Int. J. Biol. Sci. 7, 1016-1026. doi: 10.7150/ijbs.7.1016

\section{SUPPLEMENTARY MATERIAL}

The Supplementary Material for this article can be found online at: https://www.frontiersin.org/articles/10.3389/fgene.2019.00757/ full\#supplementary-material

Jeltsch, A. (2002). Beyond Watson and Crick: DNA methylation and molecular enzymology of DNA methyltransferases. Chembiochem 3 (4), 274-293. doi: 10.1002/1439-7633(20020402)3:4<274::AID-CBIC274>3.0.CO;2-S

Jin, B., and Robertson, K. D. (2013). DNA methyltransferases, DNA damage repair, and cancer. Adv. Exp. Med. Biol. 754, 3-29. doi: 10.1007/978-1-4419-9967-2_1

Kanai, Y., and Hirohashi, S. (2007). Alterations of DNA methylation associated with abnormalities of DNA methyltransferases in human cancers during transition from a precancerous to a malignant state. Carcinogenesis 28, 24342442. doi: 10.1093/carcin/bgm206

Kim, H., Kwon, Y. M., Kim, J. S., Han, J., Shim, Y. M., Park, J., et al. (2006). Elevated mRNA levels of DNA methyltransferase- 1 as an independent prognostic factor in primary nonsmall cell lung cancer. Cancer 107, 1042-1049. doi: 10.1002/ cncr.22087

Kim, D., Shin, H., Sohn, K.-A., Verma, A., Ritchie, M. D., and Kim, J. H. (2014) Incorporating inter-relationships between different levels of genomic data into cancer clinical outcome prediction. Methods (San Diego, Calif.) 67, 344-353. doi: 10.1016/j.ymeth.2014.02.003

Kropp, J., and Khatib, H. (2015). Characterization of microRNA in bovine in vitro culture media associated with embryo quality and development. J. Dairy Sci. 98, 6552-6563. doi: 10.3168/jds.2015-9510

Li, Q., Zhang, X., Li, N., Liu, Q., and Chen, D. (2017). miR-30b inhibits cancer cell growth, migration, and invasion by targeting homeobox A1 in esophageal cancer. Biochem. Biophys. Res. Commun. 485, 506-512. doi: 10.1016/j. bbrc.2017.02.016

Li, Y., Li, Y., Liu, J., Fan, Y., Li, X., Dong, M., et al. (2016). Expression levels of microRNA-145 and microRNA-10b are associated with metastasis in non-small cell lung cancer. Cancer Boil. Ther. 17, 272-279. doi: 10.1080/15384047.2016.1139242

Liao, C.-G., Kong, L.-M., Zhou, P., Yang, X.-1., Huang, J.-G., Zhang, H.-1., et al. (2014). miR-10b is overexpressed in hepatocellular carcinoma and promotes cell proliferation, migration and invasion through RhoC, uPAR and MMPs. J. Transl. Med. 12, 234. doi: 10.1186/s12967-014-0234-x

Lin, R.-K., Hsu, H.-S., Chang, J.-W., Chen, C.-Y., Chen, J.-T., and Wang, Y.-C. (2007). Alteration of DNA methyltransferases contributes to 5'CpG methylation and poor prognosis in lung cancer. Lung Cancer 55, 205-213. doi: 10.1016/j.lungcan.2006.10.022

Lin, X., Beckers, E., Mc Cafferty, S., Gansemans, Y., Joanna Szymańska, K., Chaitanya Pavani, K., et al. (2019). Bovine embryo-secreted microRNA-30c is a potential non-invasive biomarker for hampered preimplantation developmental competence. Front. Genet. 10, 315. doi: 10.3389/fgene.2019.00315

Liu, Z., Zhu, J., Cao, H., Ren, H., and Fang, X. (2012). miR-10b promotes cell invasion through RhoC-AKT signaling pathway by targeting HOXD10 in gastric cancer. Int. J. Oncol. 40, 1553-1560. doi: 10.3892/ijo.2012.1342

Liu, W., Niu, Z., Li, Q., Pang, R. T. K., Chiu, P. C. N., and Yeung, W. S.-B. (2016). MicroRNA and embryo implantation. Am. J. Reprod. Immunol. 75, 263-271. doi: 10.1111/aji.12470

Loginov, V. I., Pronina, I. V., Burdennyi, A. M., Pereyaslova, E. A., Braga, E. A., Kazubskaya, T. P., et al. (2017). Role of methylation in the regulation of apoptosis genes APAF1, DAPK1, and BCL2 in breast cancer. Bull. Exp. Boil. Med. 162, 797-800. doi: 10.1007/s10517-017-3716-Z

Luo, S.-S., Ishibashi, O., Ishikawa, G., Ishikawa, T., Katayama, A., Mishima, T., et al. (2009). Human villous trophoblasts express and secrete placenta-specific microRNAs into maternal circulation via exosomes. Biol. Reprod. 81, 717-729. doi: 10.1095/biolreprod.108.075481

Ma, Y. (2018). The challenge of microRNA as a biomarker of epilepsy. Curr. Neuropharmacol. 16, 37-42. doi: 10.2174/1570159X15666170703102410

Mahdipour, E., Charnock, J. C., and Mace, K. A. (2011). Hoxa3 promotes the differentiation of hematopoietic progenitor cells into proangiogenic Gr-1+CD11b+ myeloid cells. Blood 117, 815. doi: 10.1182/ blood-2009-12-259549 
McDonald, J. S., Milosevic, D., Reddi, H. V., Grebe, S. K., and AlgecirasSchimnich, A. (2011). Analysis of circulating microRNA: preanalytical and analytical challenges. Clin. Chem. 57, 833. doi: 10.1373/ clinchem.2010.157198

Mitchell, P. S., Parkin, R. K., Kroh, E. M., Fritz, B. R., Wyman, S. K., PogosovaAgadjanyan, E. L., et al. (2008). Circulating microRNAs as stable blood-based markers for cancer detection. Proc. Natl. Acad. Sci. 105, 10513. doi: 10.1073/ pnas. 0804549105

Mondou, E., Dufort, I., Gohin, M., Fournier, E., and Sirard, M. A. (2012). Analysis of microRNAs and their precursors in bovine early embryonic development. MHR Basic Sci. Reprod. Med. 18, 425-434. doi: 10.1093/molehr/gas015

Nakayama, I., Shibazaki, M., Yashima-Abo, A., Miura, F., Sugiyama, T., Masuda, T., et al. (2013). Loss of HOXD10 expression induced by upregulation of miR$10 \mathrm{~b}$ accelerates the migration and invasion activities of ovarian cancer cells. Int. J. Oncol. 43, 63-71. doi: 10.3892/ijo.2013.1935

Okada, Y., and Yamaguchi, K. (2017). Epigenetic modifications and reprogramming in paternal pronucleus: sperm, preimplantation embryo, and beyond. Cell. Mol. Life Sci. 74, 1957-1967. doi: 10.1007/s00018-016-2447-z

Ortiz-Escribano, N., Szymańska, K. J., Bol, M., Vandenberghe, L., Decrock, E., Van Poucke, M., et al. (2017). Blocking connexin channels improves embryo development of vitrified bovine blastocysts. Biol. Reprod. 96, 288-301. doi: 10.1095/biolreprod.116.144121

Park, H.-J., Yu, E., and Shim, Y.-H. (2006). DNA methyltransferase expression and DNA hypermethylation in human hepatocellular carcinoma. Cancer Lett. 233, 271-278. doi: 10.1016/j.canlet.2005.03.017

Peng, J. Y., An, X. P., Fang, F., Gao, K. X., Xin, H. Y., Han, P., et al. (2016). MicroRNA-10b suppresses goat granulosa cell proliferation by targeting brain-derived neurotropic factor. Domest. Anim. Endocrinol. 54, 60-67. doi: 10.1016/j.domaniend.2015.09.005

Poole, C. J., Zheng, W., Lodh, A., Yevtodiyenko, A., Liefwalker, D., Li, H., et al. (2017). DNMT3B overexpression contributes to aberrant DNA methylation and MYC-driven tumor maintenance in T-ALL and Burkitt's lymphoma. Oncotarget 8, 76898-76920. doi: 10.18632/oncotarget.20176

Qu, K., Zhang, X., Lin, T., Liu, T., Wang, Z., Liu, S., et al. (2017). Circulating miRNA-21-5p as a diagnostic biomarker for pancreatic cancer: evidence from comprehensive miRNA expression profiling analysis and clinical validation. Sci. Rep. 7, 1692. doi: 10.1038/s41598-017-01904-z

Rezsohazy, R., Saurin, A. J., Maurel-Zaffran, C., and Graba, Y. (2015). Cellular and molecular insights into Hox protein action. Development 142, 1212. doi: 10.1242/ dev. 109785

Rhee, I., Bachman, K. E., Park, B. H., Jair, K.-W., Yen, R.-W. C., Schuebel, K. E., et al. (2002). DNMT1 and DNMT3b cooperate to silence genes in human cancer cells. Nature 416, 552-556. doi: 10.1038/416552a

Robertson, K. D. (2005). DNA methylation and human disease. Nat. Rev. Genet. 6, 597. doi: $10.1038 / \operatorname{nrg} 1655$

Rosenbluth, E. M., Shelton, D. N., Wells, L. M., Sparks, A. E. T., and Van Voorhis, B. J. (2014). Human embryos secrete microRNAs into culture media-a potential biomarker for implantation. Fertil. Sterility 101, 1493-1500. doi: 10.1016/j.fertnstert.2014.01.058

Santos, F., Hendrich, B., Reik, W., and Dean, W. (2002). Dynamic reprogramming of DNA methylation in the early mouse embryo. Dev. Biol. 241, 172-182. doi: 10.1006/dbio.2001.0501

Shah, N., and Sukumar, S. (2010). The Hox genes and their roles in oncogenesis. Nat. Rev. Cancer 10, 361. doi: 10.1038/nrc2826

Shivakumar, M., Lee, Y., Bang, L., Garg, T., Sohn, K.-A., and Kim, D. (2017). Identification of epigenetic interactions between miRNA and DNA methylation associated with gene expression as potential prognostic markers in bladder cancer. BMC Med. Genomics 10, 30-30. doi: 10.1186/ s12920-017-0269-y

Stenvinkel, P., Karimi, M., Johansson, S., Axelsson, J., Suliman, M., Lindholm, B., et al. (2007). Impact of inflammation on epigenetic DNA methylation-a novel risk factor for cardiovascular disease? J. Internal Med. 261, 488-499. doi: 10.1111/j.1365-2796.2007.01777.x

Su, D.-M., Ellis, S., Napier, A., Lee, K., and Manley, N. R. (2001). Hoxa3 and Pax1 regulate epithelial cell death and proliferation during thymus and parathyroid organogenesis. Dev. Biol. 236, 316-329. doi: 10.1006/dbio.2001.0342

Talbot, D., Jaenisch, R., Sha, M., Li, E., Benner, J., Hornstra, L., et al. (1997). Baculovirus-mediated expression and characterization of the full-length murine DNA methyltransferase. Nucleic Acids Res. 25, 4666-4673. doi: 10.1093/nar/25.22.4666

Taminiau, A., Draime, A., Tys, J., Lambert, B., Vandeputte, J., Nguyen, N., et al. (2016). HOXA1 binds RBCK1/HOIL-1 and TRAF2 and modulates the TNF/ NF-KB pathway in a transcription-independent manner. Nucleic Acids Res. 44, 7331-7349. doi: 10.1093/nar/gkw606

Tan, Y., Gan, M., Fan, Y., Li, L., Zhong, Z., Li, X., et al. (2018). miR-10b-5p regulates 3T3-L1 cells differentiation by targeting Apol6. Gene 687, 36-49. doi: 10.1016/j. gene.2018.11.028

Tsumura, A., Hayakawa, T., Kumaki, Y., Takebayashi, S.-I., Sakaue, M., Matsuoka, C., et al. (2006). Maintenance of self-renewal ability of mouse embryonic stem cells in the absence of DNA methyltransferases Dnmt1, Dnmt3a and Dnmt3b. Genes Cells 11, 805-814. doi: 10.1111/j.1365-2443.2006.00984.x

Uysal, F., Ozturk, S., and Akkoyunlu, G. (2017). DNMT1, DNMT3A and DNMT3B proteins are differently expressed in mouse oocytes and early embryos. J. Mol. Histol. 48, 417-426. doi: 10.1007/s10735-017-9739-y

Valadi, H., Ekstrom, K., Bossios, A., Sjostrand, M., Lee, J. J., and Lotvall, J. O. (2007). Exosome-mediated transfer of mRNAs and microRNAs is a novel mechanism of genetic exchange between cells. Nat. Cell Biol. 9, 654-659. doi: $10.1038 /$ ncb 1596

Vallböhmer, D., Brabender, J., Yang, D., Schneider, P. M., Metzger, R., Danenberg, K. D., et al. (2006). DNA methyltransferases messenger RNA expression and aberrant methylation of $\mathrm{CpG}$ islands in non-small-cell lung cancer: association and prognostic value. Clin. Lung Cancer 8, 39-44. doi: 10.3816/CLC.2006.n.031

Vandenberghe, L. T. M., Heindryckx, B., Smits, K., Szymanska, K., Ortiz-Escribano, N., Ferrer-Buitrago, M., et al. (2018). Platelet-activating factor acetylhydrolase 1B3 (PAFAH1B3) is required for the formation of the meiotic spindle during in vitro oocyte maturation. Reprod. Fer. Develop 30, 1739-1750. doi: 10.1071/ RD18019

Vandesompele, J., De Preter, K., Pattyn, F., Poppe, B., Van Roy, N., De Paepe, A., et al. (2002). Accurate normalization of real-time quantitative RT-PCR data by geometric averaging of multiple internal control genes. Genome Biol. 3 . research0034.1. doi: 10.1186/gb-2002-3-7-research0034

Wang, J., Walsh, G., Liu, D. D., Lee, J. J., and Mao, L. (2006). Expression of DDNMT3B variants and its association with promoter methylation of $\mathrm{p} 16$ and RASSF1A in primary non-small cell lung cancer. Cancer Res. 66, 8361. doi: 10.1158/0008-5472.CAN-06-2031

Wang, G. G., Cai, L., Pasillas, M. P., and Kamps, M. P. (2007). NUP98-NSD1 links H3K36 methylation to Hox-A gene activation and leukaemogenesis. Nat. Cell Biol. 9, 804. doi: 10.1038/ncb1608

Wang, H., Liu, G., Shen, D., Ye, H., Huang, J., Jiao, L., et al. (2015). HOXA1 enhances the cell proliferation, invasion and metastasis of prostate cancer cells. Oncol. Rep. 34, 1203-1210. doi: 10.3892/or.2015.4085

Wang, Y., Zhang, Z.-X., Chen, S., Qiu, G.-B., Xu, Z.-M., and Fu, W.-N. (2016). Methylation status of SP1 sites within miR-23a-27a-24-2 promoter region influences laryngeal cancer cell proliferation and apoptosis. Biomed Res. Int. 2016, 2061248-2061248. doi: 10.1155/2016/2061248

Wang, S., Wu, W., and Claret, F. X. (2017). Mutual regulation of microRNAs and DNA methylation in human cancers. Epigenetics 12, 187-197. doi: 10.1080/15592294.2016.1273308

Wardwell-Ozgo, J., Dogruluk, T., Gifford, A., Zhang, Y., Heffernan, T. P., van Doorn, R., et al. (2014). HOXA1 drives melanoma tumor growth and metastasis and elicits an invasion gene expression signature that prognosticates clinical outcome. Oncogene 33, 1017-1026. doi: 10.1038/onc.2013.30

Watanabe, D., Suetake, I., Tada, T., and Tajima, S. (2002). Stage- and cell-specific expression of Dnmt3a and Dnmt3b during embryogenesis. Mech. Dev. 118, 187-190. doi: 10.1016/S0925-4773(02)00242-3

Wu, H., and Zhang, Y. (2014). Reversing DNA methylation: mechanisms, genomics, and biological functions. Cell 156, 45-68. doi: 10.1016/j. cell.2013.12.019

Wydooghe, E., Heras, S., Dewulf, J., Piepers, S., Van den Abbeel, E., De Sutter, P., et al. (2014). Replacing serum in culture medium with albumin and insulin, transferrin and selenium is the key to successful bovine embryo development in individual culture. Reprod. Fer. Develop 26, 717-724. doi: 10.1071/RD13043

Xing, J., Stewart, D. J., Gu, J., Lu, C., Spitz, M. R., and Wu, X. (2008). Expression of methylation-related genes is associated with overall survival in patients with non-small cell lung cancer. Br. J. Cancer. 98, 1716. doi: 10.1038/sj.bjc.6604343 
Ye, K., Wang, S., Wang, J., Han, H., Ma, B., and Yang, Y. (2016). Zebularine enhances apoptosis of human osteosarcoma cells by suppressing methylation of ARHI. Cancer Sci. 107, 1851-1857. doi: 10.1111/cas.13088

Zha, T.-Z., Hu, B.-S., Yu, H.-F., Tan, Y.-F., Zhang, Y., and Zhang, K. (2012). Overexpression of HOXA1 correlates with poor prognosis in patients with hepatocellular carcinoma. Tumor Biol. 33, 2125-2134. doi: 10.1007/ s13277-012-0472-6

Zhang, X., Zhu, T., Chen, Y., Mertani, H. C., Lee, K. O., and Lobie, P. E. (2003). Human growth hormone-regulated HOXA1 is a human mammary epithelial oncogene. J. Biol. Chem. 278, 7580-7590. doi: 10.1074/jbc. M212050200

Zhang, Y., Fang, J., Zhao, H., Yu, Y., Cao, X., and Zhang, B. (2018). Downregulation of microRNA-1469 promotes the development of breast cancer via targeting HOXA1 and activating PTEN/PI3K/AKT and Wnt/ $\beta$-catenin pathways. J. Cell. Biochem. 120, 5097-5107. doi: 10.1002/jcb.27786

Zhang, S., Chen, X., Wang, F., An, X., Tang, B., Zhang, X., et al. (2016). Aberrant DNA methylation reprogramming in bovine SCNT preimplantation embryos. Sci. Rep. 6, 30345-30345. doi: 10.1038/srep30345
Zhen, L., Li, J., Zhang, M., and Yang, K. (2016). MiR-10b decreases sensitivity of glioblastoma cells to radiation by targeting AKT. J. Boil. Res. Thessalonike Greece 23, 14-14. doi: 10.1186/s40709-016-0051-x

Zhu, Q., Gong, L., Wang, J., Tu, Q., Yao, L., Zhang, J.-R., et al. (2016). miR-10b exerts oncogenic activity in human hepatocellular carcinoma cells by targeting expression of CUB and sushi multiple domains 1 (CSMD1). BMC Cancer 16, 806-806. doi: 10.1186/s12885-016-2801-4

Conflict of Interest Statement: The authors declare that the research was conducted in the absence of any commercial or financial relationships that could be construed as a potential conflict of interest.

Copyright $\odot 2019$ Lin, Pavani, Smits, Deforce, Heindryckx, Van Soom and Peelman. This is an open-access article distributed under the terms of the Creative Commons Attribution License (CC BY). The use, distribution or reproduction in other forums is permitted, provided the original author(s) and the copyright owner(s) are credited and that the original publication in this journal is cited, in accordance with accepted academic practice. No use, distribution or reproduction is permitted which does not comply with these terms. 